\title{
MANFAAT PENGGUNAAN ALKITAB BERGAMBAR TERHADAP PERKEMBANGAN KEROHANIAN ANAK FUTURE CENTERUSIA 7-9 TAHUN DI BULUH AWAR
}

\author{
Romini \\ Email:elisabethromini@yahoo.co.id. \\ Sekolah Tinggi Agama Kristen Terpadu-PESAT \\ dan \\ Ida Deteriana Harefa \\ Email: Idadestariana01.harefa@gmail.com \\ Sekolah Tinggi Agama Kristen Terpadu-PESAT
}

\begin{abstract}
Spiritual development of Future Center children aged 7-9 years in Buluh Awar is still not well developed, due to several factors between the family environment and Future Center teacher services that are still monotonous. Less interesting learning especially when carrying out spiritual development activities, the teacher only tells stories and does not using interesting props. With the formulation of the problem: How to use a picture Bible on Future Centre program for children, How is the spiritual development of the Future Center program for children, And Are the benefits of using the picture Bible beneficial to the spiritual development on Future Centre program for children in Buluh Awar? The research method used is qualitative research methods by collecting data through observation and interviews. Based on the results of observations and interviews, after use of the picture Bible Spirituality of children can develop well After the implementation of the use of the pictorial Bible, can be obtained through observations with criteria: categories not developing 0 , enough to develop 1 child, developing 6 and 10 highly developed categories of highly developed children.The results of interviews about the benefits of the use of picture Bibles for the spiritual development of children in the Future Centerprogram at aged 7-9 years in Buluh Awar namely easier for children to read and understand the Word of God, learning the benefits of picture Bibles for the spiritual development of children, not monotonous and spiritual that develops affect the character values of children. From this achievement shows that the final results of research on the benefits of the use of picture Bible on the spiritual of children aged 7-9 years in Buluh Awar children are able to have a positive influence on the spiritual development of children.
\end{abstract}

Keywords: Future Center, children aged 7-9 years; picture Bible; Spiritual development

\begin{abstract}
ABSTRAKSI
Perkembangan spiritual anak-anak Future Center berusia 7-9 tahun di Buluh Awar masih belum berkembang dengan baik, karena beberapa faktor antara lingkungan keluarga, pelayanan Sekolah Minggu dan layanan guru Future Center yang masih monoton.Pembelajaran yang kurang menarik terutama ketika melakukan kegiatan pengembangan spiritual,seperti guru hanya bercerita dan tidak menggunakan alat peraga. Dengan rumusan masalahnya: Bagaimana cara penggunaan Alkitab bergambar kepada anak Future Center, Bagaimana perkembangan spiritual anak-anak Future Center, dan apakah
\end{abstract}


manfaat menggunakan Alkitab bergambar bagi perkembangan rohani anak-anak masa Future Center di Buluh Awar? Metode penelitian yang digunakan adalah metode penelitian kualitatif dengan mengumpulkan data melalui observasi dan wawancara. Dari hasil pengamatan dan wawancara, setelah penggunaan Alkitab bergambar, Spiritual anak dapat berkembang dengan baik lewat penerapan penggunaan Alkitab bergambar, dapat diperoleh melalui pengamatan dengan kriteria: kategori tidak berkembang 0, cukup berkembang 1 anak, berkembang 6 anak termasuk dan 10 kategori anak-anak yang sangat berkembang. Hasil dari wawancara tentang manfaat penggunaan Alkitab bergambar untuk perkembangan spiritual anak-anak di Future Center berusia 7-9 tahun di Buluh Awar menemukan bahwa lebih mudah bagi anak-anak untuk membaca dan memahami Firman Tuhan, belajar manfaat dari Alkitab bergambar untuk perkembangan spiritual, tidak monoton, serta spiritual yang berkembang mempengaruhi nilai karakter dari anak-anak. Dari pencapaian ini menunjukkan bahwa hasil akhir penelitian tentang manfaat penggunaan Alkitab bergambar terhadap kerohanian anak usia yaitu anak mampu memiliki pengaruh positif terhadap perkembangan spiritual anak.

Kata kunci: Future Center, Anak usia 7-9 tahun; Alkitab Bergambar; Perkembangan spiritual

\section{PENDAHULUAN}

Anak (Child) adalah asset bangsa. Masa depan bangsa dimasa yang akan datang berada ditangan anak sekarang.Allah sudah memberi mandat bagi umat Israel dalam kitab Ulangan 6:7 "Haruslah engkau mengajarkannya berulang-ulang kepada anak-anakmu dan membicarakannya apabila engkau duduk di rumahmu, apabila engkau sedang dalam perjalanan, apabila engkau berbaring dan apabila engkau bangun".Memperkenalkan akanAllah kepada anak-anak menjadi tanggungjawab setiap orang Kristen baik itu orangtua, guru dan hamba Tuhan.

Secara garis besar yang memengaruhi perkembangan rohani anak dimulai dari lingkungan keluarga, sekolah, teman bermain dan juga lingkungan masyarakat. Hal ini dimanfaatkan penulis untuk bisa ambil bagian dalam mengembangkan kerohanian anak khususnya dalam program anak Future Cente rusia 7-9 tahun di Buluh Awar. Berdasarkan pengamatan perkembangan kerohanian yang dilakukan, beberapa faktor yang memengaruhi perkembangan kerohanian anak Future Center yaitu factor keluarga, dan lingkungan masyarakat seperti, kurangnya perhatian orang tua kepada anak, sibuk bekerja, belum sepenuhnya menjadi orang tua rohani bagi anak, serta pengaruh pergaulan lingkungan yang kurang baik (seperti minum-minuman keras, judi, dan perkataan-perkatan buruk disekitar).

Terbangunnya aspek spiritual yang baik akan membawa pengaruh besar terhadap keseluruhan aspek kehidupan anak baik itu perkembangan moral, psikososial, kognitif. Pengajaran yang diperoleh 
anak dari orangtua sebagai teladan, lingkungan masyarakat sebagai tempat bersosialisasi dan guru rohani sebagai pembimbing untuk memperkenalkan Allah kepada anak.

Tujuan utama seorang pelayan anak dalam pelayanan adalah membawa anakanak mengenal Kristus dan menolong anak bertumbuh dewasa secara rohani. Pelayanan anak berjalan kurang menarik atau monoton akan menjadi tidak efektif dalam proses pengembangan spiritual. Hal ini disebabkan kurangnya para pelayan anak yang memiliki latar belakang pendidikan anak dan kepedulian orang tua terhadap pertumbuhan rohani anak. Hal ini dapat dilihat dari pelayanan yang dilakukan seperti, penyampaian cerita Firman Tuhan yang disampaikan kurang efektif, tidak menggunakan alat bantu cerita atau alat peraga agar anak lebih memahami apa yang disampaikan serta diajarkan, sehingga nilai-nilai Firman Tuhan yang disampaikan bisa mereka mengerti. Menyampaikan cerita Firman Tuhan tanpa alat bantu atau alat peraga, membuat anak kebingungan atau cenderung bosan, sehingga menyebabkan apa yang disampaikan kepada anak, tidak menarik dan hal ini membuat mereka mengerti.
Menurut ilmu pendidikan kita memiliki kemampuan, 20\% dari apa yang di dengar, tetapi $50 \%$ dari apa yang kita dengar dan lihat, 70\% dari apa yang kita dengar, lihat dan ulangi atau diskusikan dan 90\% dari apa yang kita dengar, kita lihat, diskusikan dan kita lakukan. ${ }^{1}$ Mendengar saja itu masih kurang efektif bagi anak yang belum memiliki kemampuan daya serap yang baik. Hal ini berdampak terhadap daya tangkap dan daya ingat anak-anak terhadap Firman Tuhan. Kemampuan dalam menyerap informasi dari apa yang didengar sangat terbatas untuk dikelola, sehingga diperlukan alat bantu dalam penyampaian cerita Firman Tuhan pada anak. Alat bantu yang digunakan ialah buku Alkitab bergambar. Dengan buku Alkitab bergambar diharapkan mampu digunakan menjadi alat bantu yang efektif dalam menyampaikan cerita Firman Tuhan. Anak akan lebih mudah memahami dan menangkap apa yang disampaikan, sehingga anak-anak makin berkembang kerohaniannya.

Oleh sebab itu penelitian ini diberi judul "Manfaat Penggunaan Alkitab Bergambar terhadap Perkembangan Kerohanian anak Future Center Usia 7-9 Tahun di Buluh Awar .

\section{Future Center}

\footnotetext{
${ }^{1}$ Ruth Laufer, Anni Dyck, Pedoman Pelayanan Anak, (Surabaya:1994), hal. 106
} 
Program Future Center (FC) adalah program utama dalam pelayanan PESAT (Pelayanan Desa Terpadu). Program Future Center (FC) adalah program pemuridan holistic anak pada usia 0-18 tahun. memiliki misi memuridkan anak desa seutuhnya untuk mencapai puncak potensiya, dengan tujuan membangun generasi pemimpin dari desa-desa di Indonesia. ${ }^{2}$ Dalam program Future Center Yayasan Pesat membagi menjadi beberapa bagian rentang usia dalam pelayanan anak, usia 0-2 tahun SBP (Stimulan Better Parent), 3-6 Tahun EDP (Explore And Discovery Program) bergerak di Kelompok bermain dan Taman kanak-kanak, 6- 11 tahun ISP(Ignite Spark Program), 11-18 Tahun NDP (Nuture Dream Program). Namun, dalam penelitian ini berfokus pada program ISP (6-11 tahun) khususnya usia anak 7-9 tahun. Dimana program Design $\&$ Architecture Future Center yang ingin dikembangkan dalam usia ini adalah:

a. Pada usia ini anak-anak dibimbing untuk dapat menemukan dan mengasah potensi dirinya semaksimal mungkin.

b. Program Terpadu (kegiatan di luarsekolah) berupa bimbingan op Cit. hal.3 belajar, pemberian motivasi, pendalaman rohani melalui kurikulum terpadu yang disiapkan, retreat, camp, dll.

c. Anak percaya diri,mampu menumbuhkan \& mengembangkan keberanian anak menyadari kasih dan rancangan Tuhan dalam hidupnya. $^{3}$

Dengan mengambil bagian untuk mengembangkan kerohanian anak melalui program yang sudah ada, program Future Center menerapkan Pelayan anak yang bertujuan agar anak-anak dapat dilayani secara holistic (tubuh, jiwa dan roh), supaya anak-anak didik memiliki potensi yang utuh di dalam Kristus. Bercerita melalui media Alkitab bergambar di harapkan dapat meningkatkan kerohanian anak FC usia 7-9 tahun di Bulu Awar.

\section{Alkitab Bergambar dan kegunaan.}

Alkitab di dalambahasa Inggris disebut Bible. Menurut KBBI, Alkitab adalah kitab suci agama Kristen yang terdiri atas Perjanjian Lama dan Perjanjian Baru. 4 Alkitab bergambar adalah sekumpulan cerita yang diambil dari Alkitabkemudian disusun dengan disertai media gambar. Alkitab bergambar lebih 
diperlukan untuk mempermudah pembaca memahami Firman. Dalam penelitian ini Alkitab bergambar adalah Alkitab yang berisi cerita singkat yang terdiri dari gambar dan pertanyaan yang diterbitkan oleh lembaga Yayasan Pondok Sentosa sebagai bahan ajar dalam proses meningkatkan kerohanian anak usia 7-9 tahun.

Kegunaan gambar Alkitab adalah sebagai berikut: ${ }^{5}$

1. Untuk menjelaskan latar belakang kebudayaan yang terdapat pada tempat dan waktu yang berbeda dalam Alkitab.

2. Pada saat mengulang isi Alkitab, gambar-gambar dapat digunakan untuk memberikan pertanyaan kepada murid.

3. Kita dapat mengajukan pertanyaan yang bersifat tantangan pada murid melalui gambar, dan murid dipimpin untuk berpikir seolah-olah mereka berada dalam situasi tersebut.

4. Mengajukan soal-soal diskusi, agar murid-murid diberi

${ }^{5}$ http://pepak.sabda.org/26/feb/2004/anak kreasi_gambar_dalam_mengajar; hari senin, 18 Februari 2019, jam 23.35 kesempatan untuk bisa berpartisipasi secara maksimal.

5. Dapat dipakai sebagai alat untuk mengajar murid menghafal ayat dalam Alkitabdan dapat dipakai sebagai alat aktivitas murid: berdasarkan gambar yang ada, guru dapat memikirkan aktivitas-aktivitas yang bisa diberikan kepada murid sehingga dapat belajar dengan lebih mendalam.

Untuk model anak-anak, ayat-ayat yang dapat disampaikan melalui ceritacerita Alkitab harus selalu menarik. Cerita yang bersambung akan membantu anakanak untuk setia mengikutinya. ${ }^{6}$ Bercerita adalah suatu kegiatan yang dilakukan seseorang secara lisan kepada orang lain dengan alat atau tanpa alat, tentang apa yang harus disampaikan dalam bentuk pesan, informasi atau hanya sebuah dongeng yang untuk didengarkan dengan rasa senang, karena orang yang menyajikan cerita tersebut menyampaikan dengan menarik. ${ }^{7}$ Tujuan metode bercerita adalah: Memunculkan perhatian (Luk. 8:49), menjelaskan suatu prinsip/ajaran (Luk.

${ }^{6}$ Makmur Halim, Model-Model Penginjilan Yesus, (Jawa Timur:2003), hal. 195 ${ }^{7}$ KONVERGENSI,edisi 20/VOLUME V/April, (Sang Surya Media:2017), hal. 79 
10:30-35), masuk ke dalam pengajaran (Luk. 15), dan menerapkan kebenaran (Luk. 6:47-49).

Fungsi gambar dalam Alkitab yaitu, dapat dipakai untuk mempersatukan suatu rangkaian cerita, anak langsung melihat apa yang sedang diceritakan, anak mengenal tempat yang disebut dalam Perjanjian Lama dan Perjanjian Baru, dan agar anak mudah mengingat dengan baik tokoh dalam cerita Alkitab. ${ }^{8}$ Jadi, Alkitab bergambar adalah buku yang berisi tentang cerita-cerita Firman Tuhan yang disertai gambar untuk memudahkan anak dalam memahami Alkitab.

Sasaran Alkitab bergambar adalah anak. Allah memiliki rencana yang sempurna bagi anak-anak. ${ }^{9}$ Artinya Allah memiliki rencana kepada setiap manusia temasuk anak. Oleh karena itu, anak harus diberi pengajaran yang benar dan diberi dasar yang kokoh sejak dini sehinggaanak akan mengenal dan menerima Yesus Kristus dengan sungguh-sungguh.

Roy B. Zuck dalam bukunya berjudul Precious in His Sightsebagaimana dikutip oleh Dan Brewter memberikan rincian terhadap banyaknya kata "anak", "anak-anak", dan "masa kanak-kanak" yang muncul dalam Alkitab.

${ }^{8}$ Ruth Laufer, Anni Disp, Op Cit, hal. 107-

${ }^{9}$ Igrea Siswanto, Op Cit, hal. 2
Kata "anak" muncul sebanyak 121 kali, kata "anak-anak" muncul sebanyak 448 kali, kata-kata "anak/anak laki-laki” muncul sebanyak 2.700 kali, kata "anak sulung" muncul sebanyak 100 kali, katakata "anak laki-laki dan anak perempuan" sebanyak 196 kali, dan kata-kata "masa kanak-kanak" muncul sebanyak 4 kali. ${ }^{10}$ Alkitab menunjukkan dengan jelas peran anak dalam seluruh penggenapan rencana-rencana Allah bagi umat manusia, termasuk dalam karya penyelamatanNya. ${ }^{11}$ Sasaran utama Alkitab adalah "Anak". Allah memiliki rencana yang sempurna bagi anak-anak. ${ }^{12}$ Dalam hal ini termasuk anak FC di usia 7-9 tahun sudah mampu mengambil keputusan yang benar dalam hidupnya untuk menerima Yesus sebagai Juruselamatnya.

\section{Perkembangan Spiritual.}

Definisi spiritual setiap manusia dipengaruhi oleh pengalaman hidup, keyakinan dan kebudayaan.Menurut Kamus Besar Bahasa Indonesia kata Spiritual berarti berhubungan dengan atau bersifat kejiwaan secara rohani.Perkembangan

\footnotetext{
${ }^{10}$ Tim KTAK Anak Bersinar Bangsa Gemilang Jaringan Peduli Anak Bangsa, Teologia Anak, (PT. Suluh Cendikia :2018), hal. 41

${ }^{11}$ TriBudiarjo, Pelayanan Anak Yang Holistik, (Yogyakarta: 2011), hal. 54

${ }^{12}$ Igrea Siswanto, Op Cit, hal. 2
} 
(Development)adalah proses yang dialamiindividumenujutingkatkedewasaan yang berlangsungsecarasistematik dan berkesinambunganbaik pada aspekfisikmaupunpsikis. ${ }^{13}$ Kata spiritual” diartikan sebagai kejiwaan, rohani, batin, mental, dan modal, sedangkan "spritualitas" adalah hal mengenai spiritual. Kompetensi spiritual berkenaan dengan kemampuan dan kecakapan guru PAK dalam aspek kerohanian, yang harus dimiliki dan termanifestasi dalam setiap pembelajaran PAK. ${ }^{14}$ Mengajari kebaikan dan kasih Allah agar dapat hidup dalam kepercayaan terhadap kebenaran untuk bertumbuh semakin dewasa dalam iman. Aktivitas rohani adalah aktivitas yang membukakan seseorang akan pengalamannya terhadap kehadirat Allah melalui doa, renungan, membaca Alkitab, dan datang ke gereja. ${ }^{15}$ Secara rohani anak mulai mengenal pokok-pokok inti iman, bila anak secara teratur diajari mengenai iman, melalui doa serta pengajaran Alkitab yang benar. Dengan demikian, kebenaran Firman Tuhan merupakan dasar teguh peserta didik dalam pertumbuhan rohaninya dan guru diberikan

\footnotetext{
${ }^{13}$ Yudrik Jahja, Psikologi Perkembangan, (Jakarta:2011), hal. 29

${ }^{14}$ Johanes W. Hasugian, Menjadi Guru PAK Profesional Melalui Supervisi Pendidikan Agama Kristen, (Medan:2016), hal. 50

15 Sih Gagas, Saat Teduh Khusus Setahun 365 Hari Menjadi Murid Sejati Kristus, (Jakarta: 2010), hal. 156
}

tanggungjawab sebagai pembimbing spiritual dalam mengajarkan kebenaran Firman Tuhan. Faktor penting lainnya ialah keluarga yang penuh kasih dan hidup dalam lingkungan Kristen yang sehat. Kemungkinan besar mereka akan bertemu dengan Allah yang hidup dan imannya berkembang secara mendalam serta semakin mantap. ${ }^{16}$

Dalam hal ini kata kerohanian lebih mengarah kepada kepribadian dan sifatsifat Allah yang tercermin dalam diri anak pada programFuture Center usia 7-9 tahun di Buluh Awar. Jadi, perkembangan rohani anak yang dimaksud di sini adalah sikap/ karakter anak yang makin menunjukkan perkembangan dalam kepribadian dan mencerminkan sifat-sifat Allah dalam kehidupannya dan hidup menurut kebenaran Firman melalui iman percaya. Penjelasan menurutbeberapa ahli bahwa pengembangan kerohanian anak adalah aktivitas perkembangan secara rohani sehingga anak mengalami kematangan iman, mengenal penciptanya dan menjalin hubungan intim dengan Allah. Indikator yang dilakukan dalam pengembangan kerohanian anak yakni melalui doa, pembacaan firman, beribadah dan

\footnotetext{
${ }^{16}$ Judith Allen Shelly, Kebutuhan Rohani Anak, (Bandung:2003), hal. 22
} 
mengenalkan sifat-sifat Allahyang ada (mengasihi, menolong, memberi).

Karakteristik perkembangan moral anak usia 7-9 tahun menurut Paulus Lie antara lain: Moral perilaku yang baik, dinilai dari apa yang menyenangkan atau apa yang dapat membantu orang lain, anak cenderung tidak menentang terhadap apa yang dinilainya wajar, Ia mencari persetujuan dari orang di sekitarnya tentang apa yang baik atau tidak baik untuk dilakukannya, Ia senang dapat menaati dan memelihara peraturan yang pasti. ${ }^{17}$ Perbuatan yang benar adalah jika tugas kewajibannya sudah dilakukannya. Selain itu perbuatan yang benar adalah jika ia menghormati otoritas (orangtua,guru). Sedangkan Perkembangan Spiritual AnakAntara lain: Anak mulai megenal rasa takut, memiliki Dasar-dasar iman kepercayaan, Memahami gagasan-gagasan keagamaan bersifat abstrak, Anak dapat mengerti bahwa Allah itu Mahakuasa, Konsep tentang Allah adalah kasih dan pencipta alam semesta dan Mengerti tentang apa itu dosa. ${ }^{18}$

Penggunaan Alkitab bergambar seperti yang tertera di atas, Alkitab yang berisi Firman Allah disertai gambargambar yang menarik memudahkan bagi

\footnotetext{
${ }^{17}$ Paulus Lie, Teknik Kreatif dan Terpadu dalam Mengajar, (Yogyakarta:1999), hal. 76-77

${ }^{18}$ Ibid.
}

pendidik dalam menyampaikan kebaikan kasih Allah kepada anak Future Center. Langkah ini dilakukan agar menarik perhatian anak, mudah memahami cerita Firman Tuhan yang disampaikan, dan gambaran tentang peristiwa kasih Allah melalui Firman.

\section{METODOLOGI PENELITIAN}

Metode yang digunakan dalam penelitian ini menggunakan metode penelitian kualitatif. Bogdan dan Taylor (1992) dalam bukunya V.Wiratna menjelaskan bahwa penelitian kualitatif adalah salah satu prosedur penelitian yang menghasilkan data deskriptif berupa ucapan atau tulisan dan perilaku orangorang yang diamati. Wiratna berpendapat bahwa pendekatan kualitatif diharapkan mampu menghasilkan uraian yang mendalam tentang ucapan, tulisan, dan atau perilaku yang dapat diamati dari suatu individu, kelompok, masyarakat, dan organisasi tertentu dalam suatu keadaan konteks tertentu yang dikaji dari sudut pandang yang utuh, komprehensif dan holistik. Data yang diperoleh dari hasil analisis secara ilmiah menggunakan metode penelitian kualitatif yang menekankan pada pemaparan berupa penggambaran yang jelas tentang fenomena atau gejala sosial yang 
tujuannya menghasilkan sebuah teori. 19 Populasi penelitian dalam pembahasan ini adalah anak Future Center Buluh Awar tahun 2018-2019 usia 7-9 tahun yang berjumlah 26 anak. Dengan jumlah responden yang diteliti yakni 17 anak usia 7-9 tahun terdiri 12 laki-laki dan 5 perempuan.

Pengumpulan data melalui observasi anak dengan indikator Perkembangan Rohani: anak mampu taat melakukan peraturan, anak mampu rajin mengikuti ibadah, anak mau berbagi dan mengasihi sesama, anak rajin berdoa baik sebelum tidur dan sebelum makan, Anak mampu bersyukur kepada Tuhan dan anak mau menolong orang lain. Wawancara kepada anak Future Center, orang tua, guru sekolah dan guru Sekolah Minggu GBKP Buluh Awar. Data kualitatif adalah data yang dinyatakan dalam bentuk deskriptif, kalimat dan gambar atau data kualitatif yang diangkakan (skoring : Selalu $=4$, sering $=3$, jarang $=2$, dan tidak pernah $=$ 1). 20 Cara menggunakan instrumen observasi, observer memberi angka sesuai tingkatannya yaitu:

\section{$\underline{\text { Tidak pernah }} \underline{\text { Jarang Sering Selalu }} 1$}

$$
34
$$

${ }^{19} \mathrm{~V}$. Wiratna Sujarweni, Metodologi Penelitian, (Yogyakarta:2014), hal. 19

${ }^{20}$ Sugiyono, Statistik Nonparametris, (Bandung:2009), hal. 4
Standar pencapaian perkembangan kerohanian anak, yakni: 1-6 = Tidak Berkembang, 7-12 = Cukup Berkembang 13-18 = Berkembang, 19-24 = Sangat Berkembang.

\section{HASIL DAN PEMBAHASAN}

Alkitab bergambar terdiri dari 138 judul cerita Perjanjian Lama dan 254 judul cerita Perjanjian Baru. Judul buku Alkitab bergambar adalah : Kisah Alkitab Anak Ceria" dari Jaringan Pelayanan Anak khusus anak usia 7-9 tahun.

Pelaksanaan penggunaan Alkitab bergambar dilakukan setiap hari Selasa setelah penerapan kurikulum Future Centerselesai dilaksanakan. Pertemuan kegiatan Future Center dilaksanakan pukul 15.00 WIB sampai pukul 17.00 WIB, maka pelaksanaan penggunakan Alkitab bergambar pada pukul 16.30 WIB. Dimana tempat pelaksanaannya di dalam ruang kelas TK Tunas Harapan Terpadu dan wisata Rohani GBKP Buluh Awar. Pelaksanaan dimulai dari bulan April sampai bulan Juni. Setiap bercerita guru menggunakan Alkitab bergambar sebagai alatbantu bercerita dan cerita di sampaikan dengan menarik. Bahasa di sesuaikan dengan usia anak. Setiap cerita disusun secara runtun di antaranya: Tuhan Pencipta, Manusia Berdosa, Banjir Besar, AbrahamTaat, Ishak Anak Perjanjian, 
Tuhan Yesus mengasihi anak-anak, Kematian Tuhan Yesus, Persembahan Seorang Anak, Kasih, Manusia Baru, dan Rajin Beribadah. Jadi, ada sebelas judul dan disampaikan dalam sebelas kali pertemuan.

Berdasarkan hasil observasi awal yang diamati oleh peneliti dengan mengamati 17 anak yang mengalami keterlambatan dalam perkembangan kerohanian anak. Keterlambatan perkembangan rohani anak terlihat dari keseharian dan tindakan anak dalam mengikuti kegiatan Future Centerdan saat di rumah. Sebagian besar anak-anak tidak disiplin berdoa, sering mengucapkan katakata kotor, menggangu teman saat beribadah, kurang memahami Firman yang disampaikan guru dan kurangnya antusias dalam mengikuti kegiatan rohani.

Ketika mewawancarai seorang anak bernama R1ia mengatakan jika kita berdoa sebelum tidur maka Yesus akan melindungi dan menjauhkan kita dari mimpi buruk. ${ }^{21}$ Anak-anak semakin mengerti bahwa Yesus adalah tempat perlindungan, penolong dan pengharapan setiap manusia.Ia selalu berdoa sebelum tidur, tetapi terkadang lupa berdoa sebelum makan ataupun saat bangun tidur.

\footnotetext{
${ }^{21}$ Hasil wawancara dengan anak Future Center R1, Selasa, 23 Juli 2019 Pukul 17.15 WIB.
}

Kemudian R2berkata bahwa mengasihi sesama dengan tidak mengejek, tidak membalas, tidak bercakap kotor sama halnya mengasihi Allah. ${ }^{22}$ R3 juga mengatakan karena Tuhan yang menciptakan tubuh kita maka harus dijaga bukan untuk memukul orang lain. ${ }^{23}$ Sebagian besar anak Future Center di Buluh Awar selalu berdoa tetapi ada yang berdoa hanya sebelum makan dan ada juga hanya berdoa sebelum tidur. Dari semuanya itu, anak sudah mempunyai dasar iman yang teguh dan takut akan Tuhan. Anak mengalami perkembangan kerohanian yang baik atau positif dan bahkan memengaruhi karakter anak.

Berdasarkan penggunaan Alkitab Bergambar yang terdiri beberapa fokus utama dalam melakukan penelitian yakni anak mampu taat terhadap peraturan, anak rajin mengikuti ibadah anak, anak mau berbagi dan mengasihi Allah, anak rajin berdoa sebelum makan dan tidur, anak mampu bersyukur kepada Tuhan dan anak mau menolong. Sebelum melakukan penggunaan Alkitab bergambar standar perkembangan kerohanian anak hanya dalam kategori berkembang yakni terdiri atas dua belas anak dan ada lima anak

\footnotetext{
${ }^{22}$ Hasil wawancara dengan anak Future Center R2, Selasa, 23 Juli 2019 Pukul 14.35 WIB

${ }^{23}$ Hasil wawancara dengan anak Future CenterR3, Rabu, 24 Juli 2019 Pukul 16.00 WIB
} 
yang dikategorikan cukup berkembang yakni AD, EB, Geo, MK, dan WH. Namun, setelah penggunaan Alkitab bergambar anak yang sangat berkembang cepat diantaranya, AG, CL, EB, ES, FX, GB, JK, LD, PS, dan RP. Anak yang berkembang yakni AD, AL, HG, GE, MK dan PH. Akan tetapi ada satu anak bernama WH yang masih cukup berkembang.

Hal ini menunjukkan bahwa Alkitab bergambar sangat bermanfaat dan efektif dalam perkembangan kerohanian anak Future Center usia 7-9 tahun di Buluh Awar dan dinyatakan mampu memberi manfaat positif terhadap perkembangan kerohanian anak khususnya anak Future Centerusia 7-9 tahun di Buluh Awar berjumlah 17 anak.

Setelah mewawancarai Ibu Yasani Lahagu sebagai guru Future Center mengatakan, bahwa jika bercerita tidak menggunakan gambar terlebih cerita Alkitab proses belajar mengajar sangat monoton atau tidak menarik dan anak cepat bosan apa lagi jika guru yang mengajar tidak mempunyai keahlian dalam bercerita. Keahlian guru dalam menggunakan gambar saat bercerita membuat cerita yang disampaikan mampu menarik perhatian anak untuk mendengar guru serta mampu memahami gambar yang sudah diperhatikan.

Menurut pendapat Ibu Yasani Lahagu manfaat setelah penggunaan Alkitab bergambar pada anak Future Center Buluh Awar usia 7-9 tahun, yakni anak-anak mampu memahami ciptaan Tuhan, serta silsilah yang ada dalam Alkitab seperti Adam dan Hawa, mengenal tokoh-tokoh Alkitab, terlebih mengembangkan tingkat spiritual anak untuk mengenal diri sebagai anak Tuhan dan ciptaan Tuhan yang paling istimewa. Perkembangan rohani yang berkembang dari anak Future Center Buluh Awar usia 7-9 tahun ialah anak-anak sudah mampu bersyukur tentang kepribadiannya yang unik dan berpotensi, bangga dengan diri sendiri serta mampu mendedikasikan hidupnya untuk menolong dan menghargai orang lain dan mengakui Yesus sebagai Tuhan Juruselamat dalam hidupnya. $^{24}$

Begitu pula yang dikatakan oleh Ibu Desilina Laia, bahwa anak sangat cepat bosan dan tidak fokus mendengar cerita yang disampaikan guru bila tidak menggunakan gambar saat bercerita.Gambar membuat menarik perhatian anak untuk mendengarkan guru

${ }^{24}$ Hasil Wawancara Kepada Guru Future Center Buluh Awar Yasani Lahagu, S.Pd, Senin, 22 Juli 2019 Pukul 11.30 WIB 
serta mampu memahami gambar yang sudah diperlihatkan.Manfaat setelah penggunaan Alkitab bergambar kepada anak Future Center Buluh Awar yaitu anak mampu memahami ciptaan Tuhan, serta silsilah yang ada dalam Alkitab seperti Adam dan Hawa.Perkembangan kerohanian anak yang terlihat, anak mampu bersyukur dalam kehidupan seharihari, anak mampu bersyukur dengan ciptaan Tuhan yang anak nikmati. ${ }^{25}$

Ibu Karyamanis Laia juga sependapat bahwa bercerita tanpa gambar merupakan proses belajar mengajar yang monoton atau tidak menarik sehingga anak cepat bosan, sebaliknya bercerita menggunakan gambar sangat menyenangkan bagi anak-anak, serta membuat mereka memiliki rasa penasaran dengan gambar berikutnya. Manfaat setelah penggunaan Alkitab bergambar kepada anak Future CenterBuluh Awar yakni anak-anak mudah untuk mengingat kembali cerita dan tokoh-tokoh Alkitab.Perkembangan kerohanian yang terlihat dari anak Future Center Buluh Awar salah satunya selalu bersyukur dan mau memberikan yang terbaik buat Tuhan

\footnotetext{
${ }^{25}$ Hasil Wawancara Kepada Guru Future Center Buluh Awar Desilina Laia, Senin, 22 Juli 2019 Pukul 11.50WIB
}

seperti tokoh Alkitab yang sudah diajarkan. ${ }^{26}$

Ibu Mermalinda Karilina Benat berpendapat bahwa bercerita tidak disertai gambar anak cepat bosan.Sedangkan dengan menggunakan gambar saat bercerita itu memudahkan anak menanggapi dan memahami alur cerita serta bersemangat untuk mendengar cerita. Manfaat setelah menggunakan Alkitab bergambar kepada anak Future Center Buluh Awar yakni anak dapat mengingat kembali nama tokoh Alkitab. Perkembangan kerohanian anak Future Center yang terlihat anak mampu hidup bersyukur kepada Tuhan apa yang anak miliki dalam kehidupan sehari-hari. ${ }^{27}$

Dari hasil observasi dan wawancara yang sudah dilakukan, dapat ditarik kesimpulan bahwa penggunaan Alkitab bergambar sangat bermanfaat terhadap perkembangan kerohanian anak Future Center di Buluh Awar usia 7-9 tahun dan sangat memberikan dampak positif pada perkembangan kerohanian anak. Manfaatnya antara lain: memudahkan anak membaca dan memahami Firman Allah, menarik perhatian anak, memberikan kesempatan

\footnotetext{
${ }^{26}$ Hasil Wawancara Kepada Guru Future Center Buluh Awar Karyamanis Laia, Senin, 22 Juli 2019 Pukul 12.00WIB

${ }^{27}$ Hasil Wawancara Kepada Guru Future Center Buluh Awar Mermalinda Karolina Benat, Senin, 22 Juli 2019 Pukul 12.20WIB
} 
anak untuk berpikir, anak mampu mengembangkan tingkat spiritualnya, dan perkembangan kerohanian anak membawa pengaruh terhadap keseluruhan kehidupan anak terlebih perkembangan karakter anak.

\section{KESIMPULAN}

Alkitab bergambar adalah Alkitab yang berisi cerita singkat disertai gambar yang menarik. Alkitab bergambar yang digunakan yaitu "Kisah Alkitab Anak Ceria" diterbitkan oleh lembaga Yayasan Pondok Sentosa. Perkembangan kerohanian (spiritual) dalam program Future Center pada anak yang dihasilkan dalam penelitian ini dapat dilihat sebagai berikut: 10 anak masuk dalam kategori sangat berkembang, selanjutnya 6 anak masuk dalam kategori berkembang dan 1 anak masuk dalam ketegori cukup berkembang. Jadi, manfaat penggunaan Alkitab bergambar terhadap kerohanian Future Center anak usia 7-9 tahun di Buluh Awar adalah memudahkan anak membaca dan memahami Firman Allah, pembelajaran yang tidak monoton, menarik perhatian anak, cerita lebih menarik, memberikan kesempatan anak untuk berpikir, anak mampu mengembangkan tingkat spiritual, dan perkembangan kerohanian anak serta membawa pengaruh terhadap keseluruhan kehidupan anak terlebih karakter anak.
Maka dapat ditarik kesimpulan bahwa Penggunaan Alkitab bergambar sangat bermanfaat terhadap perkembangan kerohanian anak Future Centerusia 7-9 tahun di Buluh Awar. 
Bob, Hartman. 2008. Cerita Alkitab Anak Kreatif. Jakarta: PT. BPK. Gunung Mulia

Budiarjo, Tri. 2011. Pelayanan Anak Yang Holistik.Yogyakarta: ANDI

Gagas,Sih. 2010. Saat Teduh Khusus Setahun 365 Hari Menjadi Murid Sejati Kristus.Jakarta: BPK Gunung Mulia

Hasugian, W, Johanes. 2016. Menjadi Guru PAK Profesional Melalui Supervisi Pendidikan Agama Kristen, Medan: STT Sumatera Utara

Jahja,Yudrik. 2011. Psikologi Perkembangan. Jakarta: PRENADA MEDIA GROUP

Laufer, Rut, et al. 1994. Pedoman Pelayanan Anak. Surabaya: Bahtera Grafika

Lie,Paulus. 1999. Teknik Kreatif dan Terpadu dalam Mengajar.Yogyakarta: Yayasan ANDI

Makalah Future Center PESAT-Terpadu. 2017.

Rahmad, Arif, Masyur. 2013. KesalahanKesalahan Guru Mengajar. Jakarta: LAKSANA

Tim KTAK Anak Bersinar Bangsa Gemilang Jaringan Peduli Anak
Bangsa, 2018, Teologia Anak, PT

Gemilang Cendikia

Shelly, Allen, Judith. 2003. Kebutuhan Rohani Anak. Bandung: Yayasan Kalam Hidup

Sugiyono, 2009, Statistik Nonparametris, Bandung : ALFABETA

Sujarweni, Wiratna V. 2014. Metodologi Penelitian. Yogyakarta: Pustaka Baru Press

Wijanarko, Jarot, et al. berani Mendisiplinkan Anak. Jakarta: Keluarga Indonesia Bahagia 